\title{
Resilience of experimentally-seeded dietary traditions in wild vervets: evidence from group fissions
}

\begin{tabular}{|r|l|}
\hline Journal: & American Journal of Primatology \\
\hline Manuscript ID & AJP-17-0051.R2 \\
\hline Wiley - Manuscript type: & Research Article \\
\hline Date Submitted by the Author: & n/a \\
\hline Complete List of Authors: & $\begin{array}{l}\text { van de Waal, Erica } \\
\text { van Schaik, Carel; University of Zurich, Anthropological Institute and } \\
\text { Museum } \\
\text { Whiten, Andrew; Centre for Social Learning and Cognitive Evolution, } \\
\text { University of St Andrews, School of Psychology }\end{array}$ \\
\hline Keywords: & social learning, group fission, tradition, field experiment, conformity \\
\hline
\end{tabular}

SCHOLARONE ${ }^{\text {'M }}$

Manuscripts 
van de Waal et al.

1 Resilience of experimentally-seeded dietary traditions in wild vervets: evidence from

2 group fissions

3

4 Short title:

$5 \quad$ Resilience of traditions in wild vervets

6

7 Erica van de Waal ${ }^{1,2,3}$, Carel P. van Schaik ${ }^{1,2}$, and Andrew Whiten ${ }^{2,3, *}$

8

$9{ }^{1}$ Anthropological Institute and Museum, University of Zurich, Winterthurerstrasse 190,

10 Zurich 8057, Switzerland

$11{ }^{2}$ Inkawu Vervet Project, Mawana Game Reserve, Swart Mfolozi, KwaZulu Natal, South

12 Africa

$13{ }^{3}$ Centre for Social Learning and Cognitive Evolution, and Scottish Primate Research Group,

14 School of Psychology \& Neuroscience, University of St Andrews, St Andrews, UK.

15

16 *Corresponding author:

17 A. Whiten

18 Centre for Social Learning and Cognitive Evolution, School of Psychology and Neuroscience,

19 University of St Andrews, South Street, St Andrews, KY16 9JP, UK.

20 Telephone: $+44(0) 1334462073$

21 e-mail: $\underline{\text { aw2@,st-andrews.ac.uk }}$ 
van de Waal et al.

\section{Abstract}

23 Controlled laboratory experiments have delivered extensive and compelling evidence for the

24 diffusion and maintenance of socially learned behavior in primates and other animals. Such

25 evidence is rarer in the wild, but we show that a behavior seeded in a majority of individuals

26 within vervet monkey (Chlorocebus pygerythus) groups may be sustained across several

27 years. Here we report results of two natural fission events in such groups that offer novel

28 evidence of the resilience of socially-transmitted group norms of behavior. Before fission,

29 high ranked females exhibited an almost exclusive adherence to a group preference among

30 two food options, originally introduced through a distasteful additive in one option, but no

31 longer present in repeated later tests. Because of rank-dependent competition, low-ranked

32 females ate more of the formerly distasteful food and so discovered it was now as palatable as

33 the alternative. Despite this experience, low ranked females who formed the splinter groups

34 then expressed a $100 \%$ bias for the preferred option of their original parent group, revealing

35 these preferences to be resilient. We interpret this effect as conformity to either the

36 preferences of high rankers or of a majority in the parent group, or both. However, given

37 fissioned individuals' familiarity with their habitat and experimental options, we question the

38 adequacy of the informational function usually ascribed to conformity and discuss alternatives

39 under a concept of 'social conformity'.

41 Keywords:

42 Social learning, group fission, tradition, field experiment, conformity

\section{$44 \quad$ Introduction}

45 A wealth of experimental studies has now demonstrated the social learning of foraging habits

46 and other behavior patterns in primates and in a wide variety of other species [Aisner \& 
47 Terkel, 1992; Galef, 1996; Galef \& Whiten, 2017; Leadbeater \& Chittka, 2009; Whiten, 2012;

48 van de Waal, Claidière, \& Whiten, 2013a; Zentall, 2012]. Such evidence is often strongest in

49 laboratory or other captive contexts where experimental controls are most tractable to arrange,

50 most importantly the provision of opportunities to learn from a model performing a novel

51 action, contrasted with a no-model control condition, and/or to learn from either of two

52 models displaying different behaviors. However, in the service of better understanding the

53 implications of such social learning in the natural lives of animals, a small but growing

54 number of experiments following these and other designs have now been engineered in the

55 more challenging circumstances of the wild, providing evidence of social learning in a range

56 of primates [Gunhold, Massen, Schiel, Souto, \& Bugnyar, 2014a; Gunhold, Whiten, \&

57 Bugnyar, 2014b; Kendal et al., 2010; Schnoell \& Fichtel, 2012; Schnoell, Dittmann, \&

58 Fichtel, 2014; van de Waal, Renevey, Favre, \& Bshary, 2010; van de Waal \& Bshary, 2011;

59 van de Waal, Borgeaud \& Whiten, 2013b] and other mammalian and avian species [Aplin et

60 al., 2015; Slagsvold \& Wiebe, 2011; Thornton \& Clutton-Brock, 2011]. Additionally, new

61 statistical techniques like social network diffusion analyses have offered complementary and

62 compelling evidence for social learning in wild birds [Aplin et al., 2015], primates [Hobaiter

63 Poisot, Zuberbühler, Hoppitt, \& Gruber, 2014] and cetaceans [Allen, Weinrich, Hoppitt, \&

64 Rendell, 2013].

65

66

Social learning of diet and foraging behavior revealed in these studies creates the

67 potential for diffusion of innovations that may spread to become traditions (group typical

68 behavior shared by group members that relies on social learning), ranging from the short term

69 to longer-term cases that may survive across generations [Mercader et al., 2007]. The

70 evidence for animal traditions is also growing, yet remains more limited than for social

71 learning per se, in part because the research required is inherently more demanding than the 
van de Waal et al.

72 basic 'A learns from B' paradigm that can be sufficient to identify social learning.

73 Experimentally identifying the diffusion of socially learned behaviors necessarily involves

74 tracking the spread across multiple individuals. Diffusion experiments of this sort have begun

75 to proliferate, again particularly in the most readily controlled laboratory and other captive

76 conditions [reviews: Mesoudi \& Whiten, 2008; Whiten, Caldwell, \& Mesoudi, 2016]. In one

77 approach, called transmission or diffusion chains, a novel behavior is seeded in a founder

78 model, who is then observed by a second individual who in turn becomes a model for the

79 next, a process repeated to track transmission over multiple potential 'cultural generations'. A

80 small set of such studies has identified transmission over as many as 6-8 such 'generations' in

81 birds [Curio, Ernst, \& Vieth, 1978], rodents [Laland \& Plotkin, 1990] and primates [Dindo,

82 Thierry, \& Whiten, 2008; Horner, Whiten, Flynn E, \& de Waal, 2006].

83

84 The control necessary to engineer such a linear series has, to our knowledge,

85 unsurprisingly defied implementation in the wild. Instead an alternative approach called 'open

86 diffusion' has been more feasible in the wild as well as in captivity [Whiten et al., 2016]. In

87 this approach, founder models are trained to perform alternative behavioral solutions to

88 naturalistic foraging problems and allowed to perform these within their group, with it being

89 'open' who watches and potentially learns from what is modelled, and the subsequent

90 behavior of observers is subsequently monitored through further experimental presentations.

91 Although only a few such studies have been completed in the wild, they have delivered

92 positive evidence of diffusion, in birds [Aplin, Sheldon, \& Morand-Ferron, 2013; Aplin et al.,

93 2015], meerkats [Thornton \& Malapert, 2009a] and monkeys [van de Waal, Claidière, \&

94 Whiten, 2015]. However the evidence for longevity in the alternatives that start to diffuse, and

95 hence form incipient traditions, is more mixed. In many such studies the seeded options tend

96 initially to be copied, but individuals' discovery of the alternative option may then erode the 
97 behavioral differences over time, such that stable alternative traditions are not necessarily

98 sustained [Kendal et al., 2010; Schnoell \& Fichtel, 2012; Thornton \& Malapert, 2009b; van de

99 Waal et al., 2015].

100 Given evidence for a basic form of 'conformity' in animal social learning, whereby

101 individuals show an adaptive bias to 'copy the majority' [Claidière \& Whiten, 2012; Haun,

102 van Leeuwen, \& Edelson, 2013], the spread and stabilization of seeded innovations in such

103 experiments may be an example of social learning that is inherently limited by a reluctance to

104 copy relatively rare behaviors, or behaviors shown only by only one or a few individuals.

105 Given this consideration, van de Waal and colleagues [2013b] explored an alternative

106 approach in which whole groups of vervet monkeys were seeded with alternative behavioral

107 options and the responses of naïve individuals experiencing these apparent existing traditions

108 were recorded. In this case the alternative behaviors involved preferring to eat maize of one

109 color, and avoiding another color that signaled an aversive and bitter taste. Once the two

110 provisions were later made equally palatable, the social learning responses of two categories

111 of naïve others (new infants and migrating mature males) were recorded. In both infants and

112 immigrant males, potent social learning was found, consistent with a 'copy the majority' bias

113 noted above, especially in the case of the migrant males [Whiten \& van de Waal, 2016]. This

114 effect therefore offers an important context in which to further investigate the resilience of

115 experimentally seeded traditions once they are common in the group. In this paper we report

116 the results of repeated testing over a period of 22 months.

118 Events in which small groups of low-ranking females split off from one large group,

119 which occurred on two different occasions, are of particular interest here because of the

120 behavior they later revealed. Female vervet monkeys have a strict linear dominance arranged

121 according to matrilines within each group [Cheney \& Seyfarth, 1990]. We observed 
van de Waal et al.

122 permanent group fissioning from our largest group (over 50 individuals before the first

123 fission) Baie Dankie (BD). The 'In Betweeners' (IB) was the first splinter group from BD

124 during our three years of studying four groups of vervet monkeys, and Intaka (IN) group was

125 the second to split from BD, after four years of studying these four groups. Since 2014 the

126 field site has experienced a drought, so fissions may occur when food resources are scarce and

127 the group has become too large to share these well. In the pioneer and only long term study

128 of a vervet monkey population in the Amboseli Park in Kenya, group fusions were

129 documented [Jaffe \& Isbell, 2010], but not group fission [Robert M. Seyfarth. pers. comm.].

130 To our knowledge we report here the first fissions in vervet monkeys. However dispersal by

131 the fissioning of an established group is well-documented in many other old world monkeys

132 [e.g., blue monkeys: Cords \& Rowell, 1986; Cords, 2012; redtail monkeys: Struhsaker \&

133 Leland, 1988; Japanese macaques: Koyama, 1970; Sugiyama, 1960; rhesus macaques:

134 Chepko-Sade \& Sade, 1979; long-tailed macaques: van Schaik \& van Noordwijk, 1988; and

135 savannah baboons: Nash, 1976].

136

137 As we show below, because of their low rank in the parent group, the individuals in

138 our splinter groups had earlier gained significant personal evidence that both food colors

139 denoted palatability and edibility. The fact that low rankers are more opportunistic and

140 flexible in their feeding behavior than high rankers was nicely demonstrated in cooperatively

141 breeding birds [Keynan, Ridley, \& Lotem, 2015]. The individuals that we studied in the

142 fissioned groups therefore provided a particularly pointed test of the effects of social learning

143 on long-term behavioral biases: would females in these splinter groups, who already deviated

144 most from the predominant pattern in their group, be the most likely to show further 
van de Waal et al.

145 degradation of the seeded bias in color preference? Or would they now more freely express

146 this bias, such that it would be traditionally maintained in the new groups?

\section{Methods}

\section{Study populations and field site}

150 The study was conducted between August 2011 and September 2014 as part of the Inkawu

151 Vervet Project (IVP) in a 12,000-hectares private game reserve, "Mawana", in KwaZulu

152 Natal, South Africa (S $28^{\circ} 00.327$; E $031^{\circ} 12.348$ ).

153 Subjects were vervet monkeys, Chlorocebus pygerythus, in six habituated groups; four

154 main groups and two splinter groups that divided from these. Such division is often referred to

155 in the literature as group fission, but here we prefer the term 'splinter' to denote that two very

156 small groups were created, leaving behind one still-large group. Aside from these small

157 splinter groups, monkeys lived in stable groups which varied from 24 to 56 individuals. In our

158 population, all groups are distributed along a river, and each group's home range overlaps

159 with those of multiple neighboring groups. Average home range size was ca. 160 hectares.

160 Groups typically contained an alpha male, subordinate males and several matrilines (females

161 and their offspring). Male vervets migrate to other groups when they are sexually mature

162 (usually around 4 years of age), while females usually remain in their natal group throughout

163 their lives. Vervet monkeys have a linear dominance hierarchy manifested in relation to

164 matrilines within the group; high-ranking females and their close relatives (mothers, sisters,

165 and daughters) are the most sought-after grooming partners [Isbell, Pruetz, Lewis, \& Young,

166 1999]. High-ranking females enjoy priority access to food during foraging bouts and have

167 access to higher quality food, which greatly increases their yearly food intake compared to

168 lower- and mid-ranking females [Whitten, 1983]. The dominance hierarchy at IVP is assessed

169 by the creation of matrices based on dyadic aggressive interactions (i.e., winner- loser) 
van de Waal et al.

170 occurring either in a natural context or around various food experiments. Using the "I\&SI"

171 method of de Vries [1998], we found that the female hierarchy was stable during the study

172 period whereas the male one was highly variable [Borgeaud, Sosa, Sueur, Bshary, \& van de

173 Waal, 2016].

174 The present study focused on two recent group splits in the largest group (including a

175 maximum of 56 individuals during this study) of our study population. First, in 2012, six

176 individuals left 'Baie Dankie' (BD) group and formed the 'In-Betweeners' (IB) group; a year

177 later, in 2013, three other individuals left BD group and formed the 'Intaka' (IN) group (Fig. 1

178 and Table 1; more details in results section). We considered each splinter group as

179 independent from their origin group, once they had been sleeping in different sleeping sites

180 than their origin group for over a month, and encounters with their origin groups were

181 agonistic, similar to those with other neighboring groups. Therefore the splinter groups had no

182 opportunities for observational learning from their original group after they fissioned. All

183 individuals were identified, mainly by facial cues. A recognition file with portrait photographs

184 as well as specific individual features (scars, color, etc) was maintained for each group.

186 Experimental procedure

187 The initial training phase consisted of three sessions, conducted at monthly intervals, where

188 two adjacent boxes of maize, one dyed blue and one pink, were offered to the monkeys. Both

189 boxes of maize where soaked overnight in plain water with food coloring in it, and in one box

190 of maize mountain aloe (Aloe marlothii) leaves were added giving it a very bitter taste and

191 smell, unpalatable for the monkeys. For two groups the aloe-treated maize was dyed blue

192 ('Lemon Tree' (LT) and 'Noha' (NH) groups), for two others, pink ('Ankhase' (AK) and BD

193 groups). These training sessions provided about $2 \mathrm{~kg}$ of maize for the groups, that ranged

194 from 30 to 43 individuals during the three training sessions, so less than $70 \mathrm{~g}$ per individual on 
195 average. Boxes were refilled to ensure that monkeys always had a choice and that as many

196 group members as possible participated. Training and test sessions were unrestricted in time,

197 lasting as long as individuals were feeding so as to have as many group members as possible

198 participating (for the initial six tests in the four large groups pre-fission: minimum length

199 97min, maximum length=4h32min; the splinter group trials: $\mathrm{IB}=31 \mathrm{~min}, \mathrm{IN}=43 \mathrm{~min})$. The side

200 of the pink and blue maize was alternated across the three training sessions and the six test

201 trials, as viewed from the camera and researchers' perspective.

202 The subsequent experimental phase for the four trained groups consisted of six test

203 trials spaced at intervals of 1, 1, 2, and 4 weeks, then approximatively 6 months, with two

204 boxes containing the same two colors of soaked maize, but with one major exception: no

205 maize was aloe-treated. Thus, all maize was now palatable and edible. Observational data

206 were collected only $48 \mathrm{~h}$ after each provisioning [van de Waal et al., 2013b].

207 After each of the two group fissions noted above, we tested the new splinter group on

208 its own as soon as possible, which took several months to achieve. The new groups did not

209 include any individual with a VHF collar so were not easy to locate, in addition to which they

210 were highly mobile in establishing their new home range and avoiding large neighboring

211 groups. They were also relatively shy so testing was delayed until winter when they were

212 most motivated to participate in test sessions. As a result tests occurred seven months after

213 fission for IB group, and over a year later for IN group.

214 As both group splits occurred in the same group, BD, which had earlier been trained to

215 eat blue maize, we designed an additional test to investigate low-ranking females in a pink-

216 trained group. We conducted these experiments on the seven lowest-ranked females of $\mathrm{NH}$

217 group, a group well habituated to human researchers. We targeted each of these females while

218 she was alone (or just with her own offspring) and offered her a small box with two

219 compartments filled with the two colors of maize. We conducted these experiments at the end 
van de Waal et al.

220 of the South African winter in September 2014, when the natural food of the vervet monkeys

221 is scarce, and the monkeys spread out after they leave the sleeping site. We presented the food

222 for a maximum of 10 minutes or until other group members approached.

223

224 Data collection and analyses

225 All experiments were recorded using a video camera on a tripod. The image included the two

226 boxes and approximately 1 meter on each side. In addition, on each minute we recorded who

227 was eating at the boxes. A minimum of two observers conducted and recorded the

228 experiments in the four trained groups. As the splinter groups were relatively shy to human

229 observers we initially conducted the experiments with the camera on a tripod without any

230 researchers nearby, and later with only one researcher in IB group, then initially with only one

231 researcher, then two, in the IN group.

232 We applied a focal sampling method during the field experiments, and where

233 necessary in supplementary video analysis, to record each individual processing (eating or

234 spitting out) up to seven pieces of maize of each color per session. Coding was unambiguous

235 as it was always conducted when feeding individuals were facing the observers and the color

236 of the maize was easily visible.

237 All statistical analyses were performed using IBM SPSS 22. Because the splinter

238 groups provided only small sample sizes, two-tailed non-parametric analyses are applied

239 throughout. Non-parametric tests are robust for our multiple measures on the same individuals

240 [Chen \& Popovich, 2002].

242 Ethics

243 The experimentation reported in this paper followed the American Society of 244 Primatologists' Principles for the Ethical Treatment of Primates. The study was registered 
van de Waal et al.

245 with Ezemvelo KZN Wildlife in South Africa and the experiment including use of aloe to

246 create a distasteful sample of food was approved by the Ethics Committee of the School of

247 Psychology and Neuroscience, University of St Andrews.

248

249 Results

250 Rank predicts adherence to modal group preferences

251 Following the original 2011 aloe training described above, we offered the choice of the two

252 colors of maize, now untreated and thus palatable, in repeat tests run up to 2014 . We found

253 that a strong correlation had emerged between the percentage of time that a female spent

254 eating the locally preferred color and her rank in the group's dominance hierarchy, with the

255 highest-rankers exclusively eating the original, always palatable color and ignoring the

256 originally aloe-tainted, but now equally palatable, alternative (Spearman correlation, N=26

257 (the females who participated in all 6 trials), Rho $=-0.730, \mathrm{P}<0.001$; Fig. 1a, see

258 supplementary Fig. 1 and video 2; Spearman correlation, N=36 (all females that participated

259 at least in 1 trial), Rho=-0.447, $\mathrm{P}=0.006$ ). Inspection of individual profiles (Fig. $1 \mathrm{~b}$ ) indicated

260 that this effect was mainly caused by the lowest ranked females in each group (boxed in

261 figure), who in the competitive context of the maize provisioning, took much more of the

262 originally distasteful but now perfectly palatable color of maize (Fig. 1b).

263

264 Change in expressed preferences of fissioned groups females

265 The recent group fissions documented above revealed a prioritization of social over personal

266 information. These fissions occurred after the behavioral patterns illustrated in Fig. 1 were

267 established. Both small splinter groups (see Table 1 for individual details) came to occupy

268 home ranges that overlapped that of the parent group, BD (Fig. 2). 
van de Waal et al.

269 Comparing the time spent eating blue versus pink maize before vs. after the group

270 fissions we found a significant change in color choices. Although all IB females ate both

271 colors in the original BD group (individual Oo is a male, see Table 1), they ate exclusively

272 blue maize during the first test after having separated from the higher rankers of their original

273 group, whose members displayed a strong preference for blue maize. The IN females

274 similarly ate both colors while still in BD but ate only blue maize during the first test after the

275 fission (Wilcoxon signed-rank test of change in percentage of blue taken, including (i) all

276 individuals of both splinter groups: Wilcoxon signed-rank test, $\mathrm{N}=9, \mathrm{Z}=-2.52, \mathrm{P}<0.02$, and (ii)

277 with only the adult females of both splinter groups: Wilcoxon signed-rank test, $N=6, Z=-2.20$,

$278 \mathrm{P}<0.05$; Fig. 3a, b, see supplementary Fig. 3).

279 The strong bias of these females towards the majority preferences of the parent BD

280 group occurred despite the fact that all had substantial direct, prior personal experience that

281 both foods were equally palatable (and some had equal or even more experience with the

282 locally non-preferred color), for they had fed on pink maize in repeated but separate episodes

283 during an average of 9.2 one-minute samples ( $. d \pm 3.3)$ spread across the experimental trials,

284 before the fission events (details in Table 2).

285

286 Control test excluding basic color preference

287 Further analyses explored and tested potential explanations for the bias. First is the possibility

288 that vervet monkeys simply have a basic preference for blue over pink food items. Because no

289 splits occurred in pink-trained groups, which would have provided cross-confirmation of the

290 results from the blue trained group, BD, we tested the seven lowest-ranking females in the

291 two pink-trained groups while they were not in association with higher-ranking competitors,

292 offering the small boxes with compartments of pink and blue maize, as described above. We

293 found an all-but-exclusive preference for pink in these solo tests (percentage time spent eating 
294 this preferred color: $\mathrm{N}=7$, median $=100$ and mean $=99.7)$, much stronger than these same

295 females had expressed in earlier group tests (Wilcoxon signed-rank test, $\mathrm{N}=7, \mathrm{Z}=-2.20$,

$296 \mathrm{P}<0.05$; Fig 4, see also supplementary Fig. 4 and video 5). This finding confirms there is no

297 general bias towards a preference for blue maize. These results are also consistent with those

298 observed after the group splits (i.e. that low-rankers prefer the majority choice, even if they do

299 not, or cannot, select it in a group setting).

300

301 Confirmation of a socially learned effect

302 A second analysis served to examine the possibility that once females had split from higher-

303 ranked group mates, the strong preference they expressed could simply be one all monkeys

304 had learned individually from their original training experience of aloe-treated food, and

305 could return to now that they had the opportunity to do so. This scenario is not supported

306 because we found that only one of the six females forming the IB and IN groups had taken

307 treated maize into her mouth during the original training events. Moreover, only one of the

308 seven low-ranking females in the pink-trained group $(\mathrm{NH})$ that were tested alone ate one piece

309 of aloe-treated maize, a single time. More generally, of the 39 females from our four groups

310 present during the original aloe training, only 20 directly sampled aloe-treated maize

311 (meaning taken in hand or mouth a piece of maize), and a similar number, 19, never touched a

312 piece of the aloe-treated maize. These 19 females that had never smelled or tasted the treated

313 maize subsequently ate for a mean percentage of time intervals $86.6 \%$ of blue maize in the

314 blue trained groups and $16.2 \%$ in the pink trained groups during 6 pre-fission tests,

315 percentages not significantly different from the $77.6 \%$ and $13.6 \%$ respectively, for the 20

316 females that had learned by direct experience of treated maize (Mann-Whitney U test, N=39,

$317 \mathrm{U}=181.5, \mathrm{P}=0.811$; Fig. 5a, b). These results indicate that for half of all the females in our

318 experiments, the persistent preference they expressed was not based on their own past direct 
van de Waal et al.

319 experience, but instead on social learning, likely resulting from often strong observational

320 cues that one alternative was very distasteful, such as monkeys throwing pink maize away or

321 spitting it out. Encounters of the splinter groups with neighboring groups, even with their

322 original group, were always aggressive. Accordingly they could never observe other groups

323 feeding on the colored maize, so there were no further opportunities for social learning. The

324 color preference must have been derived from pre-fission learning.

325 Results from a group tested with no aloe training underline the resilience that vervets

326 may display once a dietary preference is expressed by a majority. When this group, Kubu,

327 was offered the two colors of maize, the alpha male started eating pink, but the alpha female

328 started eating blue. The alpha male ate first, then the alpha female came and ate when the

329 alpha male was still eating. She was joined by two others that also ate blue. Then both alphas

330 left and the four other monkeys started eating blue. The alpha male ate only pink during the

331 first trial, but then he switched and ate only blue at the second trial, and maintained a

332 preference for blue in the following trials up to the seventh trial. Over the course of seven

333 tests this group, that never tasted any bitter-tasting aloe maize, displayed as strong and

334 resilient a preference for one color as the aloe trained groups (mean percentage of time eating

335 preferred color over trial 1 to 7 , in the four trained groups $=70.4 \%$; in Kubu group $=69.2 \%$ ).

337 Copying high-rankers or a majority?

338 A third and final issue is whether the social learning effect is based on the monkeys'

339 observation of just one or a few individuals, such as high ranked animals, or the alternative of

340 copying a majority (a criterion for 'conformity' preferred by many [Battesi, Moreno, Joly, \&

341 Mery, 2012; Henrich \& Boyd, 1998; van Leeuwen \& Haun, 2013; van Leeuwen \& Haun,

342 2014; Pike \& Laland, 2010] though not all authors [van de Waal et al., 2013b]. As Fig. 1

343 shows, a bias to copy the highest-ranked animals could produce a similar effect to copying the 
van de Waal et al.

344 majority and we cannot definitively distinguish these. However, we found that the array of

345 monkeys that others could view was consistently and repeatedly displaying a clear majority at

346 one of the two colors (Fig. 6a), and that the cumulative majority of individuals eating blue

347 that monkeys could easily have observed before the group splits rose steadily during the

348 experiments (Fig. 6b). Thus information that could inform conformity was clearly readily

349 available. In the discussion we explain why perception of these majority displays and

350 conformity to them may offer the most parsimonious explanation for the behavior of the

351 splinter group females.

352

\section{Discussion}

354 The six females in the two splinter groups, tested several months after the split, showed a

$355100 \%$ bias for the dietary preference shown by a majority of their parent group, and we have

356 presented data rejecting the possibility that this reflects an inherent color preference or an

357 earlier, individually learned preference. Accordingly these results lead us to conclude that the

358 strong preferences are socially learned traits. The existence of such dispositions could

359 potentially thus support traditions resilient to major perturbations in the social fabric of groups

360 such as the fissions we documented. Given that only one of the fissioning females had ever

361 directly mouthed aloe-treated maize and that all these individuals had direct experience that

362 both colors were palatable and had no side effects, their $100 \%$ commitment to their origin

363 group color preference is striking.

364

365

An explanation for the strength of this effect might lie in the fact that ours is so far the

366 only study to seed local habits in a majority of each group. The handful of other field

367 experiments that have seeded alternative behaviors in the wild have typically done so in only

368 single individuals initially, and these studies have tended to demonstrate initial social 
van de Waal et al.

369 learning, soon followed by corruption and erosion of group behaviors, rather than the

370 resilience so marked in our own study where we instead simulated existing customary

371 traditions [Kendal et al., 2010; Schnoell \& Fichtel, 2012; Thornton \& Malapert, 2009b; van

372 de Waal et al., 2015]. Another potential explanation is that our experiment is the only one

373 testing a preference for a food type rather than including an object or 'artificial fruit'

374 manipulation like those cited above. Using social information to make adaptive food choices

375 may be a more habitual process than learning manipulative techniques.

376

What decision rules of these females explain such effects? Two principal options

378 appear to fit our findings. One is that the fissioning females were motivated to try to act like

379 the highest ranked females they had witnessed in their parent group, who expressed the

380 strongest preference for the maize color favored by the group (Fig. 1). Such preferential

381 copying of high ranked individuals has been shown in captive primates (chimpanzees) and

382 suggested to be adaptive insofar as high ranking individuals are often the most successful

383 foragers and therefore best to copy [Kendal et al., 2015; Horner, Proctor, Bonnie, Whiten, \&

384 de Waal., 2010]. In the wild, Hobaiter and colleagues [2014] found evidence of a dominant

385 individual (the alpha male) seeding a behavior (using moss for water sponging) in a

386 chimpanzee community, and this has now spread further [Lamon, Neumann, Gruber, \&

387 Zuberbühler, 2017]. However to our knowledge, such an effect has not been shown

388 experimentally in the wild, to date. If this motivation was responsible for the effect, it

389 survived the severing of the association with these high ranking females by at least 4 months.

391 A second alternative is adopting the preference shown by a majority of the parent

392 group, a form of conformity [Haun et al., 2013], although in this case based on long term

393 memory of majority behavior in the parent group, BD. Such effects have been documented in 
394 other animals including birds [Aplin et al., 2015], and male migrants in our own study

395 population [van de Waal et al., 2013b; Whiten \& van de Waal, 2016]. In the results section we

396 documented that there was a visible majority available for the individuals to copy the color

397 choice before they fissionned (Fig. 6). However as it was logistically not feasible in the field

398 to gather data on the attention of bystanders around the colored food, we cannot discriminate

399 if this was key in the current study. We do think it feasible to experimentally test for a bias to

400 copy high rank models in future, although this is far from straightforward to engineer. We

401 suggest that of the two potential rules, this would thus appear to be the more cognitively

402 economic to implement, compared to one that requires integration of (i) knowledge of the

403 ranks of group mates; (ii) a running tally of the preferences of each and (iii) a comparison of

404 these tallies. We know that resident vervet monkeys do in fact acquire a good working

405 knowledge of rank relationships in their group [Borgeaud. van de Waal, \& Bshary, 2013;

406 Seyfarth \& Cheney, 2015], so this hypothesis deserves to be investigated and experiments to

407 do so are ongoing in our research program. In the meantime, copying the majority appears the

408 most parsimonious of the two processes likely to underlie the resilience our data demonstrate.

409 Of course the two potential rules are not mutually exclusive: both may be in operation here

410 and may mutually reinforce each other to maintain group traditions long after the original

411 conditions that created them have passed. Either way, the mechanisms involved produced a

412 remarkable resilience in the preferences established through social learning, even after major

413 changes in social context and in the face of personal information that could have led to an

414 erosion of these preferences.

415

416 A major issue therefore concerns what functions such resilient group-level preferences

417 may serve. Here we suggest that a distinction between what social psychologists call

418 informational versus normative conformity provides a helpful framework [Claidière \& 
van de Waal et al.

419 Whiten, 2012; Deutsch \& Gerard, 1955]. Informational conformity serves the function of

420 providing good, truthful information about the world; in the present context this concerns

421 which is the best of two food options to consume. Normative conformity, by contrast, serves

422 purely social functions, such as strengthening bonds with others by simply being more like

423 them, or adhering to societal or even prescribed norms. In our experiment, copying either

424 high rankers or a majority of others might in principle serve an informational function, insofar

425 as high rankers tend to eat the 'best' foods, and a majority of the group has likely converged

426 on the optimal choice too. However, neither of these rationales fit well with the circumstances

427 of the fissioning females, who already had good personal information on the palatability and

428 safety of eating either of the food colors on offer. Moreover, unlike the male migrants for

429 whom we earlier reported conformity to the new and different preferences of their adopted

430 group [van de Waal et al., 2013b] and so perhaps had need of local adaptive information, the

431 females had not moved far, partly occupying the same familiar area, and even sometimes

432 feeding on the same provisioning sites as before.

433

434 Accordingly we suggest we should explore the hypothesis that the females' behavior

435 could constitute what we here provisionally call 'social conformity'. By social conformity we

436 mean that individuals act like others not to achieve an informational function, but instead to

437 achieve a social function that derives from simply 'being like others' as suggested by the

438 bonding and identification-based observational learning (BIOL) theory [de Waal, 2001],

439 despite other options being open to them (in the present case, selecting only one of two food

440 options they know are equally palatable). Such a disposition may need no underlying complex

441 cognition, but merely the following of a motivational rule, that might have innate or learned

442 origins or both. If the rule were to preferentially act as the majority do, such conformity could

443 normally assist intra-group integration, important for a range of outcomes including 
444 coordinated travelling and foraging, and mating opportunities. If the rule were to

445 preferentially act as high-rankers do, such conformity could make performers appear of

446 superior status (we are aware that referring to conformity here deviates from the common

447 usage denoting copying a majority), but we apply it to highlight that the individual would be

448 ignoring alternative actions open to it and copying 'just to be like others', another common

449 way in which the term conformity is used.

451 'Social conformity' thus contrasts with informational conformity in a similar way as

452 does social psychologists' 'normative conformity', but we use a different term because

453 normative conformity is often taken to require a recognition that norms should be followed

454 (i.e. that norms are prescriptive and deviations may be punished), although in fact some

455 psychologists in any case divide norms into either prescriptive norms (what it is proper to do)

456 or merely descriptive norms, which describe the statistical property of what a majority do

457 (easily applied to non-human animals, as indeed we do here). In children recognition of the

458 prescriptive, normative aspect of conformity emerges early in childhood, as in experiments

459 where, for example, children object when a peer or even a puppet transgresses an arbitrary

460 conventional norm [Keupp, Behne, \& Rakoczy, 2013; Rakoczy, Warneken, \& Tomasello,

461 2008].

462

463 We speculate that the more elementary possibility we have called social conformity

464 may nevertheless turn out to be a significant phenomenon in nature, given the importance for

465 group-living animals of meshing one's social dealings with others [Silk, Alberts, \& Altmann,

466 2003; Silk, 2007; de Waal \& Lutrell, 1986]. There is evidence that primates are more

467 affiliatively disposed to those who match their own behavior [Nielsen, Collier-Baker, Davis,

468 \& Suddendorf, 2005; Paukner, Anderson, Borelli, Visalberghi, \& Ferrari, 2005; Paukner, 
van de Waal et al.

469 Suomi, Visalberghi, \& Ferrari 2009]. Social conformity effects related to this could be

470 important, for example, in explaining tendencies in birds [Catchpole \& Slater, 2008; Lachlan,

471 Janik, \& Slater, 2004], whales [Garland et al., 2011] and primates [Watson et al., 2015] for

472 vocal convergence among associating individuals. Whatever the underlying explanation for

473 the behavior we recorded in our vervet splinter groups, the strength of their inclination to

474 persist in the choice of the dietary option prevalent in their parent group despite their

475 knowledge of perfectly viable alternatives demonstrates a marked resilience in a primate

476 tradition documented in the wild.

477

478 Acknowledgements

479 This work was supported by the Swiss National Science Foundation (Sinergia grant

480 CRSI33_133040 to A.W. and C. S., P300P3_151187 and 31003A_159587 to E.W.); the

481 Society in Science - Branco Weiss Fellowship to E.W.; and the John Templeton Foundation

482 (ID 40128 to A.W.). We confirm that this research was conducted in compliance with animal

483 care regulations and applicable national laws. We are grateful to K. van der Walt for

484 permission to conduct the study in his reserve. We thank C. Borgeaud, A. van Blerk, J.

485 Botting, A. Driescher and S. Mercier for great support in the field. We are grateful to J.

486 Arsenau, A. Brotz, S. Delley, K. Gordon, M. Mignini, Z. Mills, S. Salcedo, T. Sharky, A.

487 Taucher, K. Vega, L. Violetti, and J. Watzek for assistance in data collection during

488 experimental trials. We thank L. Aplin, N. Claidiere, D. Haun, L. Hopper, E. van Leeuwen,

489 and S. Watson for comments on the manuscript. 
van de Waal et al.

\section{References}

491 Aisner, R., \& Terkel, J. (1992). Ontogeny of pine cone opening behaviour in the black rat, 492 Rattus rattus. Animal Behaviour, 44, 327-336.

493 Allen, J., Weinrich, M., Hoppitt, W., \& Rendell, L. (2013). Network-based diffusion analysis 494 reveals cultural transmission of lobtail feeding in humpback whales. Science, 340, 485495 488. (DOI:10.1126/science.1231976)

496 Aplin, L. M., Sheldon, B. C., \& Morand-Ferron, J. (2013). Milk bottles revisited: social 497 learning and individual variation in the blue tit, Cyanistes caeruleus. Animal Behaviour, $498 \quad 85,1225-1232$. (DOI:10.1016/j.anbehav.2013.03.009)

499 Aplin, L. M., Farine, D. R., Morand-Ferron, J., Cockburn, A., Thornton, A., \& Sheldon, B. C. 500 (2015). Experimentally induced innovations lead to persistent culture via conformity in $501 \quad$ wild birds. Nature, 518, 538-541. (DOI:10.1038/nature13998)

502 Battesti, M., Moreno, C., Joly, D., \& Mery, F. (2012). Spread of social information and 503 dynamics of social transmission within Drosophila groups. Current Biology, 22, 309-313. $504 \quad$ (DOI:10.1016/j.cub.2011.12.050)

505 Borgeaud, C., van de Waal, E., \& Bshary, R. (2013). Third-Party Ranks Knowledge in Wild $506 \quad$ Vervet Monkeys (Chlorocebus aethiops pygerythrus). PLoS ONE, 8:e58562.

$507 \quad$ (DOI:10.1371/journal.pone.0058562)

508 Borgeaud, C., Sosa, S., Sueur, C., Bshary, R., \& van de Waal, E. (2016). Intergroup variation 509 of social relationships in wild vervet monkeys: a dynamic network approach. Frontiers in $510 \quad$ Psychology, 7, 915. (DOI:10.3389/fpsyg.2016.00915)

511 Catchpole, C. K., \& Slater, P. J. B. (2008). Bird song: Biological themes and variations (2nd 512 ed.). Cambridge, UK: Cambridge University Press.

513 Chen, P. Y., \& Popovich, P. M. (2002). Correlation: Parametric and nonparametric

514 measures (Vol. 07-139). New York: Sage. 
van de Waal et al.

515 Cheney, D. L., \& Seyfarth, R. M. (1990). How monkeys see the world: Inside the mind of

516 another species. Chicago, IL: University of Chicago Press.

517 Chepko-Sade, B. D., \& Sade, D. S. (1979). Patterns of group splitting within matrilineal

518 kinship groups: a study of social group structure in Macaca mulatta (Cercopithecine:

519 Primates). Behavioral Ecology and Sociobiology, 5, 67-87. (DOI:10.1007/BF00302696)

520 Claidière, N., \& Whiten, A. (2012). Integrating the study of conformity and culture in humans

521 and non-human animals. Psychological Bulletin, 138, 126-145. (DOI:10.1037/a0025868)

522 Cords, M., \& Rowell, T. E. (1986). Group fission in blue monkeys of the Kakamega Forest,

523 Kenya. Folia Primatologica, 46, 70-82. (DOI:10.1159/000156239)

524 Cords M. (2012). The 30-Year Blues: What we know and don't know about life history,

525 group size, and group fission of Blue Monkeys in Kakamega Forest, Kenya. In P. M.

526 Kappeler, \& D. P. Watts (Eds.), Long-term field studies of primates. Springer Science \&

$527 \quad$ Business Media.

528 Curio, E., Ernst, U., \& Vieth, W. (1978). Cultural transmission of enemy recognition: one

529 function of mobbing. Science, 202, 899-901. (DOI:10.1126/science.202.4370.899)

530 Deutsch, M., \& Gerard, H. B. (1955). A study of normative and informational social

531 influences upon individual judgment. Journal of Abnormal and Social Psychology, 51,

532 629-636. (DOI:10.1037/h0046408)

533 Dindo, M., Thierry, \& B., Whiten, A. (2008). Social diffusion of novel foraging methods in

534 brown capuchin monkeys (Cebus apella). Proceedings of the Royal Society B: Biological

$535 \quad$ Sciences, 275, 187-193. (DOI:10.1098/rspb.2007.1318)

536 Galef Jr, B. G. (1996). Social enhancement of food preferences in Norway rats: a brief

537 review. Social learning in animals: The roots of culture, 49-64.

538 Galef, B. G. Jr., \& Whiten, A. (2017). The comparative psychology of social learning. In J.

539 Call (Ed.) G. Burghardt, I. Pepperberg, C. Snowdon, \& T. Zentall (Assoc. eds.), APA 
540 Handbook of Comparative Psychology (pp.411-440). Washington, DC, USA: American

$541 \quad$ Psychological Association.

542 Garland, E. C., Goldizen, A. W., Rekdahl, M. L., Constantine, R., Garrigue, C., Hauser, N.

543 D., ... \& Noad, M. J. (2011). Dynamic horizontal cultural transmission of humpback

$544 \quad$ whale song at the ocean basin scale. Current Biology, 21, 687-691.

$545 \quad$ (DOI:10.1016/j.cub.2011.03.019)

546 Gunhold, T., Massen, J. J. M., Schiel, N., Souto, A., \& Bugnyar, T. (2014a). Memory,

547 transmission and persistence of alternative foraging techniques in wild common

548 marmosets. Animal Behaviour, 91, 79-91. (DOI:10.1016/j.anbehav.2014.02.023)

549 Gunhold, T., Whiten, A., \& Bugnyar, T. (2014b). Video demonstrations seed alternative

550 problem-solving techniques in wild common marmosets. Biology Letters, 10(9),

551 20140439. (DOI:10.1098/rsbl.2014.0439)

552 Haun, D. B, van Leeuwen, E. J., \& Edelson, M. G. (2013). Majority influence in children and 553 other animals. Developmental cognitive neuroscience, 3, 61-71.

$554 \quad$ (DOI:10.1016/j.den.2012.09.003)

555 Henrich, J., \& Boyd, R. (1998). The evolution of conformist transmission and the emergence 556 of between-group differences. Evolution and Human Behavior, 19, 215-242.

557 (DOI:10.1016/S1090-5138(98)00018-X)

558 Hobaiter, C., Poisot, T., Zuberbühler, K., Hoppitt, W., \& Gruber, T. (2014). Social network

559 analysis shows direct evidence for social transmission of tool use in wild chimpanzees.

$560 \quad$ PLoS Biol, 12, e1001960. (DOI:10.1371/journal.pbio.1001960)

561 Horner, V., Whiten, A., Flynn, E., \& de Waal, F. B. (2006). Faithful replication of foraging

562 techniques along cultural transmission chains by chimpanzees and children. Proceedings

563 of the National Academy of Sciences of the United States of America, 103, 13878-13883.

$564 \quad$ (DOI:10.1073/pnas.0606015103) 
van de Waal et al.

565 Horner, V., Proctor, D., Bonnie, K. E., Whiten, A., \& de Waal, F. B. M. (2010). Prestige

566 affects cultural learning in chimpanzees. PLoS ONE, 5, e10625.

567 (DOI:10.1371/journal.pone.0010625)

568 Isbell, L. A., Pruetz, J. D., Lewis, M., \& Young, T. P. (1999). Rank differences in ecological

569 behavior: a comparative study of patas monkeys (Erythrocebus patas) and vervets

570 (Cercopithecus aethiops). International Journal of Primatology, 20, 257-272.

$571 \quad$ (DOI:10.1023/A:1020574504017)

572 Jaffe, K. E., \& Isbell, L. A. (2010). Changes in ranging and agonistic behavior of vervet

573 monkeys (Cercopithecus aethiops) after predator-induced group fusion. American

574 Journal of Primatology, 72(7), 634-644. (DOI: 10.1002/ajp.20821)

575 Kendal, R. L., Custance, D. M., Kendal, J. R., Vale, G., Stoinski, T.S., Rakotomalala, N. L.,

576 \& Rasamimanana, H. (2010). Evidence for social learning in wild lemurs (Lemur catta).

577 Learning \& Behavior, 38, 220-234. (DOI:10.3758/LB.38.3.220)

578 Kendal, R., Hopper, L. M., Whiten, A., Brosnan, S. F., Lambeth, S. P., Schapiro, S. J., \&

579 Hoppitt, W. (2015). Chimpanzees copy dominant and knowledgeable individuals:

580 implications for cultural diversity. Evolution and Human Behavior, 36, 65-72.

$581 \quad$ (DOI:10.1016/j.evolhumbehav.2014.09.002)

582 Keupp, S., Behne, T., \& Rakoczy, H. (2013). Why do children overimitate? Normativity is

583 crucial. Journal of Experimental Child Psychology, 116, 392-406.

$584 \quad$ (DOI:10.1016/j.jecp.2013.07.002)

585 Keynan, O., Ridley, A. R., \& Lotem, A. (2014). Social foraging strategies and acquisition of

586 novel foraging skills in cooperatively breeding Arabian babblers. Behavioral Ecology, 26,

587 207-214. (DOI:10.1093/beheco/aru181)

588 Koyama, N. (1970) Changes in dominance rank and division of a wild Japanese monkey troop

589 in Arashiyama. Primates, 11, 335-390. (DOI:10.1007/BF01730638) 
590 Lachlan, R.F., Janik, V.M., \& Slater, P.J.B. (2004). The evolution of conformity-enforcing

591 behaviour in cultural communication systems. Animal Behaviour, 68, 561-570.

$592 \quad$ (DOI:10.1016/j.anbehav.2003.11.015)

593 Laland, K. N., \& Plotkin, H. C. (1990). Social learning and social transmission of foraging

594 information in Norway rats (Rattus norvegicus). Animal Learning \& Behavior, 18, 246-

595 251. (DOI:10.3758/BF03205282)

596 Lamon, N., Neumann, C., Gruber, T., \& Zuberbühler, K. (2017). Kin-based cultural

597 transmission of tool use in wild chimpanzees. Science Advances, 3, e1602750.

$598 \quad$ (DOI:10.1126/sciadv.1602750)

599 Leadbeater, E., \& Chittka, L. (2009). Bumble-bees learn the value of social cues through $600 \quad$ experience. Biology Letters, 5, 310-312. (DOI:10.1098/rsbl.2008.0692)

601 van Leeuwen, E. J. C, \& Haun, D. B. M. (2013). Conformity in primates: fad or fact?.

602 Evolution and Human Behaviour, 34, 1-7. (DOI:10.1016/j.evolhumbehav.2012.07.005)

603 van Leeuwen, E. J. C, \& Haun, D. B. M. (2014). Conformity without majority? The case for

604 demarcating social from majority influences. Animal Behaviour, 96, 187-194.

$605 \quad$ (DOI:10.1016/j.anbehav.2014.08.004)

606 Mercader, J., Barton, H., Gillespie, J., Harris, J., Kuhn, S., Tyler, R., \& Boesch, C. (2007).

607 4,300-year-old chimpanzee sites and the origins of percussive stone technology.

608 Proceedings of the National Academy of Sciences of the United States of America, 104, 609 3043-3048. (DOI:10.1073/pnas.0607909104)

610 Mesoudi, A., \& Whiten, A. (2008). The multiple roles of cultural transmission experiments in 611 understanding human cultural evolution. Philosophical Transactions of the Royal Society 612 B: Biological Sciences, 363, 3489-3501. (DOI:10.1098/rstb.2008.0129) 
van de Waal et al.

613 Nash, L. T. (1976). Troop fission in free-ranging baboons in the Gombe Stream National

614 Park, Tanzania. American Journal of Physical Anthropology, 44, 63-78.

615 (DOI:10.1002/ajpa.1330440109)

616 Nielsen, M., Collier-Baker, E., Davis, J. M., \& Suddendorf, T. (2005). Imitation recognition

617 in a captive chimpanzee (Pan troglodytes). Animal Cognition, 8, 31-36.

$618 \quad$ (DOI:10.1007/s10071-004-0232-0)

619 Paukner, A., Anderson, J. R., Borelli, E., Visalberghi, E., \& Ferrari, P. F. (2005). Macaques

620 (Macaca nemestrina) recognize when they are being imitated. Biology Letters, 1, 219-

621 222. (DOI:10.1098/rsbl.2004.0291)

622 Paukner, A., Suomi, S. J., Visalberghi, E., \& Ferrari, P. F. (2009). Capuchinl monkeys display

623 affiliation toward humans who imitate them. Science, 325, 880-883.

$624 \quad$ (DOI:10.1126/science.1176269)

625 Pike, T. W., \& Laland, K. N. (2010). Conformist learning in nine-spined sticklebacks'

626 foraging decisions. Biology Letters, 6, 466-468. (DOI:10.1098/rsbl.2009.1014)

627 Rakoczy, H., Warneken, F., \& Tomasello, M. (2008). The sources of normativity: Young

628 children's awareness of the normative structure of games. Developmental Psychology, 44,

629 875-881. (DOI:10.1037/0012-1649.44.3.875)

630 van Schaik, C. P., van Noordwijk, M. A. (1988). Scramble and contest in feeding competition

631 among female long-tailed macaques (Macaca fascicularis). Behaviour, 105, 77-98.

$632 \quad$ (DOI:10.1163/156853988X00458)

633 Schnoell, A. V., \& Fichtel, C. (2012). Wild redfronted lemurs (Eulemur rufifrons) use social

634 information to learn new foraging techniques. Animal Cognition, 15, 505-516.

$635 \quad$ (DOI:10.1007/s10071-012-0477-y) 
636 Schnoell, A. V., Dittmann, M. T., \& Fichtel, C. (2014). Human-introduced long-term

637 traditions in wild redfronted lemurs? Animal Cognition, 17, 45-54. (DOI:10.1007/s10071-

$638 \quad 013-0636-9)$

639 Seyfarth, R. M., \& Cheney, D. L. (2015). Social cognition. Animal Behaviour, 103, 191-202.

$640 \quad$ (DOI:10.1016/j.anbehav.2015.01.030)

641 Silk, J. B., Alberts, S. C., \& Altmann, J. (2003). Social bonds of female baboons enhance

642 infant survival. Science, 302, 1231-1234. (DOI:10.1126/science.1088580)

643 Silk, J. B. (2007). Social components of fitness in primate groups. Science, 317, 1347-1351.

$644 \quad$ (DOI:10.1126/science.1140734)

645 Slagsvold, T., \& Wiebe, K. L. (2011). Social learning in birds and its role in shaping a

646 foraging niche. Philosophical Transactions of the Royal Society B: Biological Sciences,

647 366, 969-977. (DOI:10.1098/rstb.2010.0343)

648 Struhsaker, T. T., \& Leland, L. (1988). Group fission in redtail monkeys (Cercopithecuas

649 scanius) in the Kibale Forest, Uganda. In: A. Gautier-Hion, F. Bourliere, J.-P. Gautier, \&

650 J. Kingdon (Eds), A primate radiation: evolutionary biology of the African guenons (pp

651 364-388). Cambridge, U.K.: Cambridge University Press.

652 Sugiyama, Y. (1960). On the division of a natural troop of Japanese monkeys at

653 Takasakiyama. Primates, 2, 109-148. (DOI:10.1007/BF01659166)

654 Thornton, A., \& Malapert, A. (2009a). Experimental evidence for social transmission of food 655 acquisition techniques in wild meerkats. Animal Behaviour, 78, 255-264.

$656 \quad$ (DOI:10.1016/j.anbehav.2009.04.021)

657 Thornton, A., \& Malapert, A. (2009b). The rise and fall of an arbitrary tradition: an

658 experiment with wild meerkats. Proceedings of the Royal Society B: Biological Sciences, 659 276, 1269-1276. (DOI:1098/rspb.2008.1794) 
van de Waal et al.

660 Thornton, A., \& Clutton-Brock, T. (2011). Social learning and the development of individual

661 and group behaviour in mammal societies. Philosophical Transactions of the Royal

662 Society B: Biological Sciences, 366, 978-987. (DOI:10.1098/rstb.2010.0312)

663 de Vries, H. (1998). Finding a dominance order most consistent with a linear hierarchy: a new

664 procedure and review. Animal Behaviour, 55, 827-843. (DOI: 10.1006/anbe.1997.0708)

665 de Waal, F. B. M, \& Lutrell, L. M. (1986). The similarity principle underlying social bonding

666 among female rhesus-monkeys. Folia Primatologica, 46, 215-234.

$667 \quad$ (DOI:10.1159/000156255)

668 de Waal, F. B. M. (2001). The ape and the sushi master: cultural reflections of a

669 primatologist. New York, NY: Basic Books.

670 van de Waal, E., Renevey, N., Favre, C. M., \& Bshary, R. (2010). Selective attention to

671 philopatric models causes directed social learning in wild vervet monkeys. Proceedings

672 of the Royal Society of London B: Biological Sciences, 277, 2105-2111.

$673 \quad$ (DOI:10.1098/rspb.2009.2260)

674 van de Waal, E., \& Bshary, R. (2011). Social-learning abilities of wild vervet monkeys in a

675 two-step task artificial fruit experiment. Animal Behaviour, 81, 433-438.

676 (DOI:10.1016/j.anbehav.2010.11.013)

677 van de Waal, E., Claidière, N., \& Whiten, A. (2013a). Social learning and spread of

678 alternative means of opening an artificial fruit in four groups of vervet monkeys. Animal.

679 Behaviour, 85, 71-76. (DOI:10.1016/j.anbehav.2012.10.008)

680 van de Waal, E., Borgeaud, C., \& Whiten, A. (2013b). Potent social learning and conformity

681 shape a wild primate's foraging decisions. Science, 340, 483-485.

$682 \quad$ (DOI:10.1126/science.1232769) 
683 van de Waal, E., Claidière, N., \& Whiten, A. (2015). Wild vervet monkeys copy alternative

684 methods for opening an artificial fruit. Animal Cognition, 18, 617-627.

$685 \quad$ (DOI:10.1007/s10071-014-0830-4)

686 Watson, S. K., Townsend, S. W., Schel, A. M., Wilke, C., Wallace, E. K., Cheng, L., ... \&

687 Slocombe, K. E. (2015). Vocal learning in the functionally referential food grunts of

688 chimpanzees. Current Biology, 25(4), 495-499. (DOI:10.1016/j.cub.2014.12.032)

689 Whiten, A. (2012). Social learning, traditions and culture. In J Mitani, J Call, P Kappeler, R

690 Palombit, J.Silk (Eds.), The Evolution of Primate Societies (pp. 681-699). Chicago, USA:

691 Chicago University Press.

692 Whiten, A., Caldwell, C. A., \& Mesoudi, A. (2016). Cultural diffusion in humans and other 693 animals. Current Opinion in Psychology, 8, 15-21. (DOI:10.1016/j.copsyc.2015.09.002)

694 Whiten. A., \& van de Waal, E. (2016). Identifying and dissecting conformity in animals in the 695 wild: further analysis of primate data. Animal Behaviour, 122, e1-e4.

696 (DOI:10.1016/j.anbehav.2016.04.002)

697 Whitten, P. L. (1983). Diet and dominance among female vervet monkeys (Cercopithecus

698 aethiops). American Journal of Primatology, 5, 139-159. (DOI:10.1002/ajp.1350050205)

699 Zentall TR. (2012). Perspectives on observational learning in animals. Journal of

$700 \quad$ Comparative Psychology, 126, 114. (DOI:10.1037/a0025381) 
van de Waal et al.

\section{Figure legends:}

702 Figure 1: a) Correlation between adult females' rank and the average number of minutes

703 spent eating the initially palatable color during experiments 1 to 6 , for all females who

704 participated in all 6 trials. The black line represents the power trend line. Pink points represent

705 females from the two groups trained to eat pink (NH: blue line around data points, LT: black

706 line around data points), blue points represent females from blue trained groups (AK: black

707 line around data points, BD: pink line around data points). b) Time spent by each female

708 eating the initially palatable color for each group. Number in brackets next to name code

709 shows female's rank. Boxes around results highlight the reduced time spent feeding on the

710 preferred color by the lowest-ranking females of each group.

711

712 Figure 2: Map of the home ranges of two groups In Betweeners and Intaka that split from

713 Baie Dankie group.

714

715 Figure 3: Average percentage of minutes spent eating the preferred color ('local preference')

716 compared to the other color ('other') by individuals before (all recorded trials pre-fission

717 where the individuals participated) and after split ( $1^{\text {st }}$ trial) from the original BD group: a) for

718 IB individuals; b) for IN individuals.

719

720 Figure 4: Average time (in minutes) spent eating the preferred color by low-ranking females

721 of $\mathrm{NH}$, in the group context and when tested alone.

722

723 Figure 5: Average \% of observed minutes eating maize of each color in both pink- and blue-

724 trained groups: a) females that tried aloe maize during the training phase $(\mathrm{n}=20)$; $\mathrm{b})$ females

725 that never picked up a single maize piece treated with aloe $(\mathrm{n}=19)$. 
van de Waal et al.

726

727 Figure 6: a) Mean number of BD monkeys eating the preferred color (blue) and the

728 alternative color (pink) collected in 10-minute scans and expressed during the first two hours

729 in experiments 1-6. b) Mean cumulative number of BD monkeys eating the preferred color

730 (blue) and the alternative color (pink) across successive scan periods. Supplementary Fig. 6.

731 Mean cumulative number of BD monkeys eating the preferred color (blue) and the alternative

732 color (pink) across successive scan periods during the first two hours in Experiment 1. 


\section{Highlights}

- First report of group fission in vervets reveals high tradition resilience

- Initial group was trained to prefer one of two foods but low-rankers sampled non-preferred option

- After fission these monkeys ate only the parent group's preferred option 
Fig. 1

a)

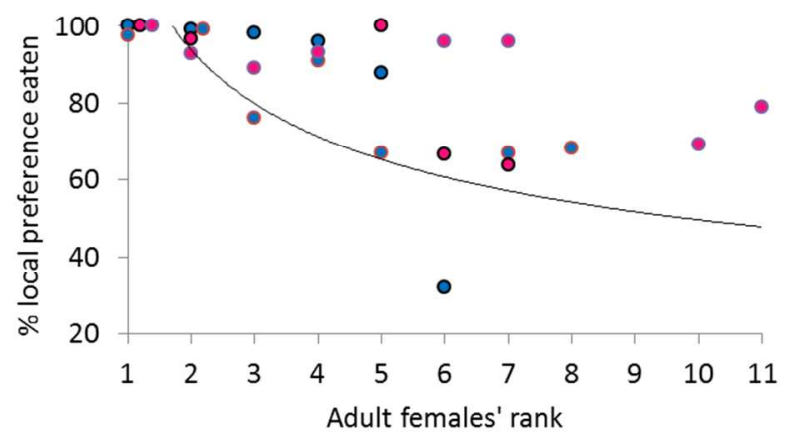

b)
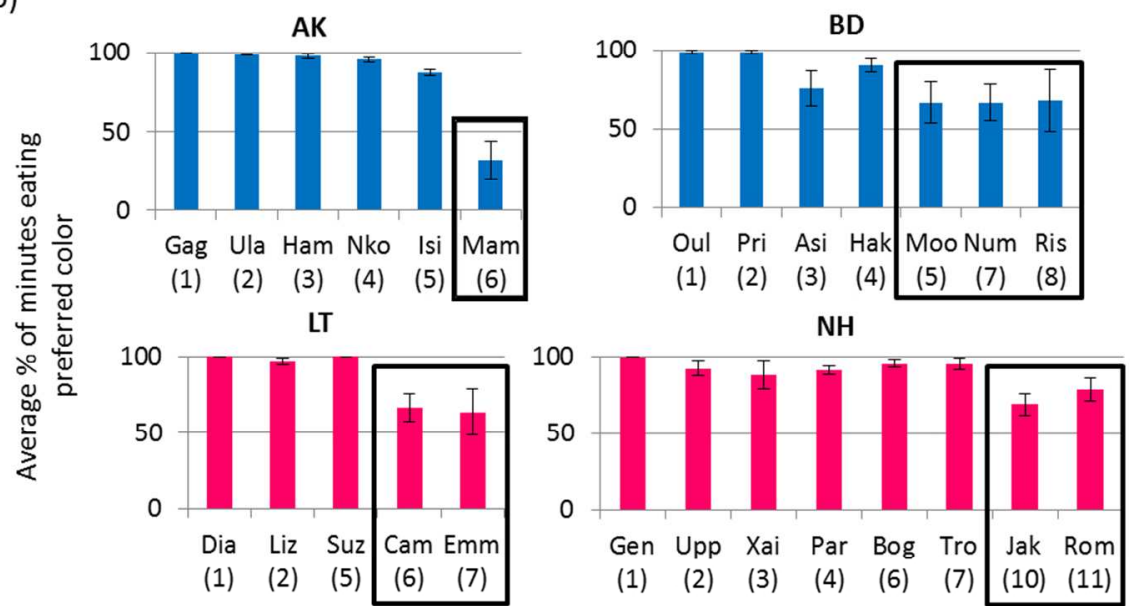

Figure 1: a) Correlation between adult females' rank and the average number of minutes spent eating the initially palatable color during experiments 1 to 6 , for all females who participated in all 6 trials. Pink points represent females from the two groups trained to eat pink ( $\mathrm{NH}$ : blue line around data points, LT: black line around data points), blue points represent females from blue trained groups (AK: black line around data points, BD: pink line around data points). b) Time spent by each female eating the initially palatable color for each group. Number in brackets next to name code shows female's rank. Boxes around results highlight the reduced time spent feeding on the preferred color by the lowest-ranking females of each group.

$$
182 \times 175 \mathrm{~mm}(150 \times 150 \mathrm{DPI})
$$




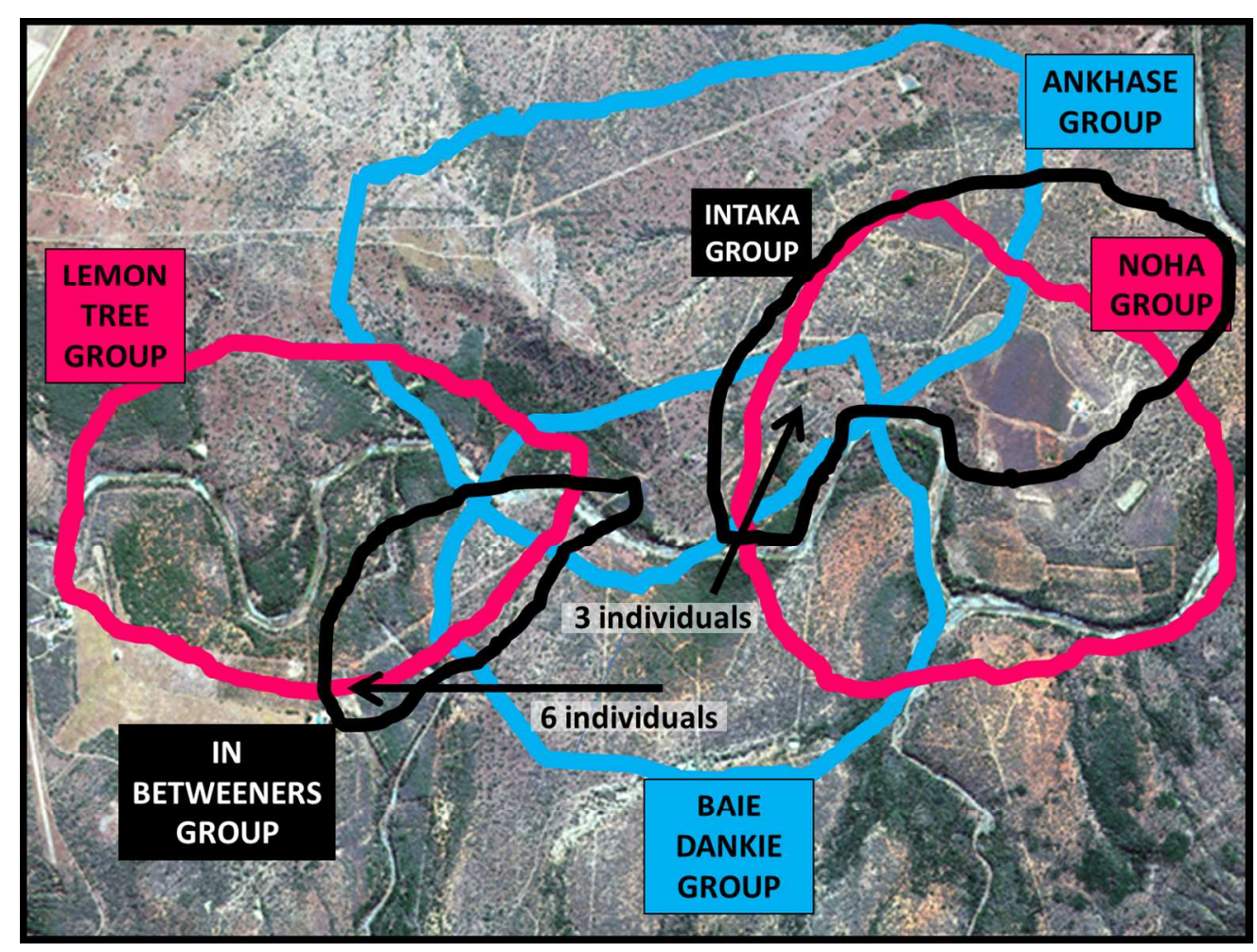

Figure 2: Map of the home ranges of two groups IB and IT that split from BD. $257 \times 193 \mathrm{~mm}(150 \times 150 \mathrm{DPI})$ 
Fig. 3

Figure 3: Average percentage of minutes spent eating the preferred color ('local preference') compared to the other color ('other') by individuals before (all recorded trials pre-fission where the individuals participated) and after split (1st trial) from the original BD group: a) for IB individuals; b) for IN individuals.

$$
170 \times 121 \mathrm{~mm}(150 \times 150 \mathrm{DPI})
$$


Fig. 4

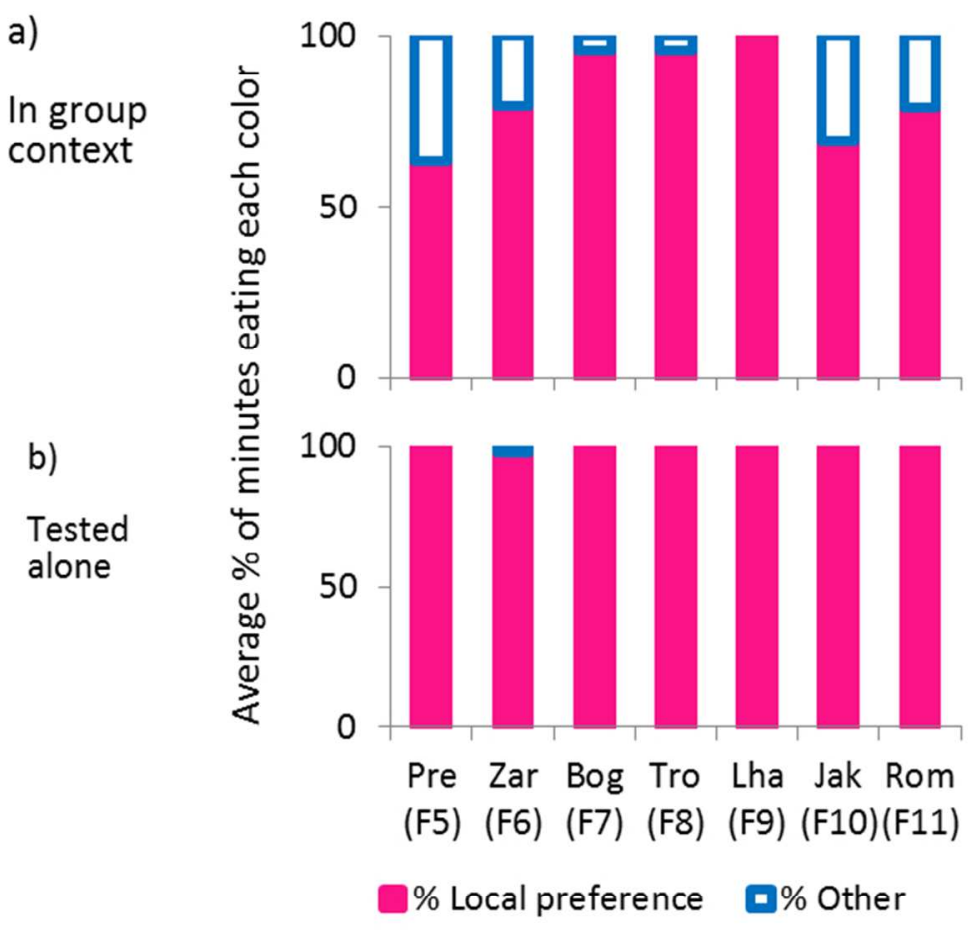

Figure 4: Average time (in minutes) spent eating the preferred color by low-ranking females of $\mathrm{NH}$, in the group context and when tested alone.

$133 \times 125 \mathrm{~mm}(150 \times 150 \mathrm{DPI})$ 
Fig. 5

a)

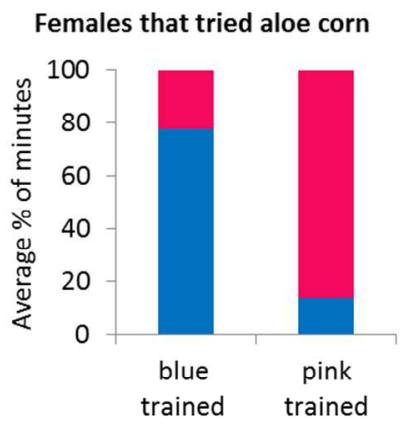

b)

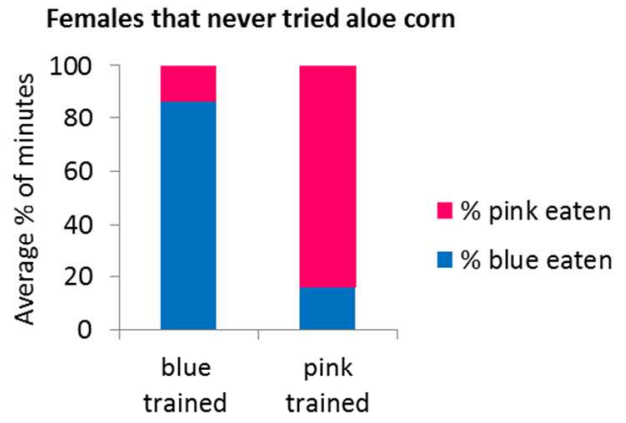

Figure 5: Average \% of observed minutes eating corn of each color in both pink- and blue-trained groups: a) females that tried aloe corn during the training phase $(n=20)$; b) females that never picked up a single corn piece treated with aloe $(n=19)$.

$$
190 \times 93 \mathrm{~mm}(150 \times 150 \mathrm{DPI})
$$


Fig. 6

a)

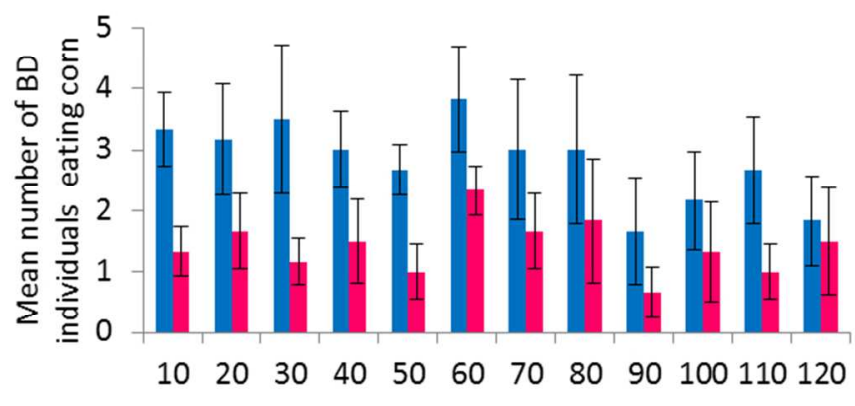

Scan every 10 minutes during 2 hours of experiment

b)

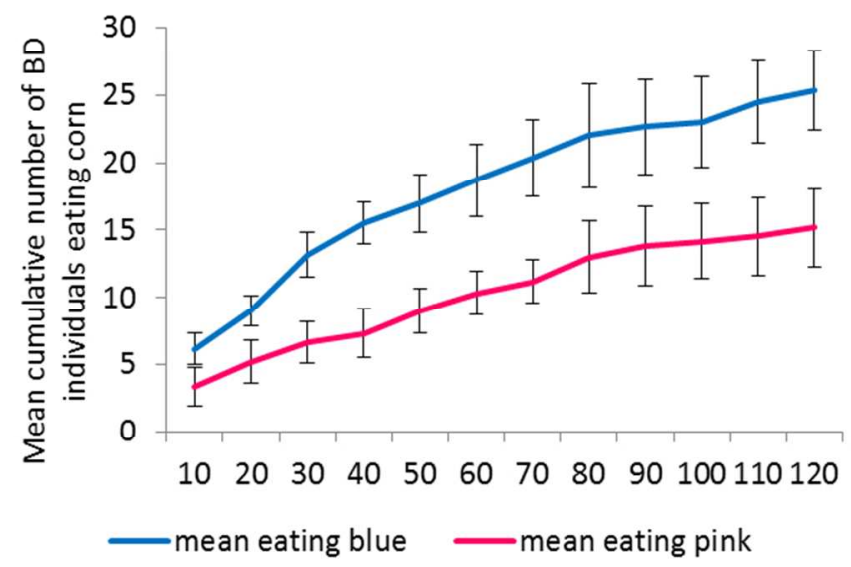

Figure 6: a) Mean number of BD monkeys eating the preferred color (blue) and the alternative color (pink) collected in 10-minute scans and expressed during the first two hours in experiments 1-6. b) Mean cumulative number of BD monkeys eating the preferred color (blue) and the alternative color (pink) across successive scan periods.

$$
153 \times 166 \mathrm{~mm}(150 \times 150 \mathrm{DPI})
$$




\section{Table 1.}

\section{Composition of the two splinter groups}

\begin{tabular}{|c|c|c|c|c|}
\cline { 2 - 5 } \multicolumn{1}{c|}{} & ID code & Age & Sex & rank in BD \\
\hline \multirow{4}{*}{ IB } & Kai & AD & F & 9 \\
\cline { 2 - 5 } & Dag & AD & F & 10 \\
\cline { 2 - 5 } & Tip & AD & F & 11 \\
\cline { 2 - 5 } & Fee & JU3 & F & $>11$ \\
\cline { 2 - 5 } & Kon & JU2 & F & 9 \\
\cline { 2 - 5 } & Oo & AD & M & 3 \\
\hline \multirow{4}{*}{ IN } & Wie & AD & F & 9 \\
\cline { 2 - 5 } & Bem & AD & F & 10 \\
\cline { 2 - 5 } & Vro & AD & F & 11 \\
\hline
\end{tabular}

\section{Table footnote:}

Group composition of the two groups split from 'Baie Dankie' (BD) group; name codes (2 letter for males, 3 for females), age class $(\mathrm{AD}=$ adult, $\mathrm{JU}=$ juvenile with age in years), sex ( $\mathrm{F}=$ female, $\mathrm{M}=$ male) and rank just before leaving $\mathrm{BD}$ (offspring have the rank of their mother). 'In-Betweeners' (IB) last experiment in BD group was 19th June 2012; the experiment after was 31st January 2013. 'Intaka' (IN) last experiment in BD group was 15th December 2012 and test after split was 15th March 2014. 


\section{Table 2.}

Number of minutes splinter group females spent eating (a) pink or (b) blue in their origin group before they split off, during each of the six test sessions and in total.

a)

\begin{tabular}{|l|l|l|l|l|l|l|l|}
\hline TEST & 1 & 2 & 3 & 4 & 5 & 6 & total \\
\hline Kai & - & 2 & - & 3 & - & - & $\mathbf{5}$ \\
\hline Dag & - & - & 0 & 2 & - & - & $\mathbf{2}$ \\
\hline Tip & - & 1 & 4 & 6 & - & - & $\mathbf{1 1}$ \\
\hline Wie & - & - & - & 4 & - & 10 & $\mathbf{1 4}$ \\
\hline Bem & - & - & - & 5 & - & 14 & $\mathbf{1 9}$ \\
\hline Vro & - & - & - & 0 & 0 & 4 & $\mathbf{4}$ \\
\hline
\end{tabular}

b)

\begin{tabular}{|l|l|l|l|l|l|l|l|}
\hline TEST & 1 & 2 & 3 & 4 & 5 & 6 & total \\
\hline Kai & - & 4 & - & 15 & - & - & $\mathbf{1 9}$ \\
\hline Dag & - & - & 2 & 7 & - & - & $\mathbf{9}$ \\
\hline Tip & - & 5 & 1 & 1 & - & - & $\mathbf{7}$ \\
\hline Wie & - & - & - & 9 & - & 4 & $\mathbf{1 3}$ \\
\hline Bem & - & - & - & 2 & - & 2 & $\mathbf{4}$ \\
\hline Vro & - & - & - & 22 & 12 & 28 & $\mathbf{6 2}$ \\
\hline
\end{tabular}

